\title{
Meat quality prediction using Raman spectroscopy and chemometrics
}

\author{
Marius Nache ${ }^{1 *}$, Rico Scheier ${ }^{2}$, Heiner Schmidt ${ }^{2}$, Bernd Hitzmann ${ }^{1}$ \\ From 9th German Conference on Chemoinformatics \\ Fulda, Germany. 10-12 November 2013
}

The feasibility of using Raman spectroscopy as a fast and non-invasive method to monitor the quality parameters in pork meat has been investigated. For this application an online prediction methodology has not been established yet. Based on raw Raman spectra of 10 pork semimembranosus muscles a range of data pre-processing and multivariate calibration methodology have been used to develop online predictive models for the meat quality parameters: the lactate and $\mathrm{pH}$. The linear and nonlinear algorithms studied were comparatively analysed for speed, robustness and accuracy. Identifying the best "efficiency" evaluation procedure represented the final milestone of the present study. Thus with a cross-validated $\mathrm{r}^{2}$ value for both $\mathrm{pH}$ and lactate of 0.97 , a RMSECV of $4.5 \mathrm{mmol} / \mathrm{l}$ for the lactate prediction and 0.06 units for the $\mathrm{pH}$ prediction, locally weighted regression provided the most accurate and robust model. This prove the feasibility of using Raman spectroscopy for online meat quality control applications.

\begin{abstract}
Authors' details
${ }^{1}$ Department of Process Analytics and Cereal Technology, Institute of Food Science and Biotechnology, University of Hohenheim, Stuttgart, 70599, Germany. ${ }^{2}$ Research Centre of Food Quality, University Bayreuth, Kulmbach, 95326, Germany.
\end{abstract}

Published: 11 March 2014

doi:10.1186/1758-2946-6-S1-P21

Cite this article as: Nache et al.: Meat quality prediction using Raman spectroscopy and chemometrics. Journal of Cheminformatics 2014 6(Suppl 1):P21.

\footnotetext{
* Correspondence: Nache.M@uni-hohenheim.de

'Department of Process Analytics and Cereal Technology, Institute of Food Science and Biotechnology, University of Hohenheim, Stuttgart, 70599, Germany

Full list of author information is available at the end of the article
}

\section{Publish with ChemistryCentral and every scientist can read your work free of charge \\ "Open access provides opportunities to our colleagues in other parts of the globe, by allowing anyone to view the content free of charge." \\ W. Jeffery Hurst, The Hershey Company. \\ - available free of charge to the entire scientific community \\ - peer reviewed and published immediately upon acceptance \\ - cited in PubMed and archived on PubMed Central \\ - yours - you keep the copyright \\ Submit your manuscript here: \\ http://www.chemistrycentral.com/manuscript/

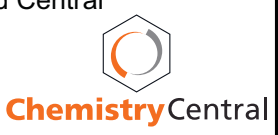

